\title{
Flowering and Non-Flowering Spur Leaf Characteristics of 'Amasya' Apple and Its Comparison with Other Cultivars
}

\author{
Ayşe Nilgün ATAY ${ }^{1}$ (i) Ersin ATAY ${ }^{1}$
}

${ }^{1}$ Burdur Mehmet Akif Ersoy University, Food Agriculture and Livestock School, Department of Crop and Livestock Production, Horticulture Program, 15030, Burdur, Turkey

\section{Article History}

Received 07 December 2021

Accepted 02 February 2022

First Online 07 February 2022

Corresponding Author

E-mail: anatay@mehmetakif.edu.tr

\begin{abstract}
Understanding the attributes of spur leaves in apple trees is essential to gain more insight into the complex process of fruit development and quality. However, limited literature is available about the spur leaf characteristics of the 'Amasya' apple cultivar. In this work, the Soil Plant Analysis Development (SPAD) and leaf area were investigated in flowering and non-flowering spur leaves of 'Amasya' and six common apple cultivars. Significant differences among cultivars were observed for the SPAD and spur leaf area. The median SPAD readings in 'Amasya' were 32.63 and 26.23 for the flowering and nonflowering spurs, respectively, which were the relatively low values among studied cultivars. The maximum SPAD value was measured in flowering spurs of 'Cripps Pink' (45.03). SPAD values were found to be lower in non-flowering spurs compared with flowering ones for all the studied cultivars, which confirms that decline in chlorophyll content coincided with a gradual decline in productivity. A notably significantly lower spur leaf area was found in 'Amasya', whereas the highest spur leaf area was in 'Cripps Pink'. However, no statistical difference was observed between flowering and non-flowering spur leaf areas within the same cultivars. The present results provided a general framework of SPAD and spur leaf areas in 'Amasya' and other apple cultivars when spurs had flowers or not. Knowledge of these characteristics provides a basis for building a model related to yield elaboration of apple trees.
\end{abstract}

\section{Introduction}

Unlike shoot leaves, spur leaves are produced firstly on an apple tree in spring and enlarged from the spurs, non-extension and shorter shoots (Proctor and Palmer, 1991; Elsysy and Hirst, 2017). These primary spur leaves can usually make up 30 to 60 percent of the total leaf area on an apple tree, depending on the cultivar, whereas they are the main part of the tree canopy until fruit set (Van den Ende, 2018). Therefore, they are strongly associated with the fruit set, fruit growth, quality, and long-term productivity (Ferree and Palmer, 1982; Proctor and Palmer, 1991; Ferree et al., 2001). In addition, studying spur leaf attributes of the cultivars is needed to understand these complex processes of agronomic importance.

'Amasya' apple is characterized by its unique eating quality and aroma (Atay et al., 2016). It also faces several production constraints such as nonfunctional tree architecture, low production, alternate bearing, earlier bloom, and poor coloration (Atay et al., 2018). For this reason, a better definition of its spur leaf habits would be of great relevance for overcoming these constraints, which complicate the management of the cultivar.

SPAD, also called chlorophyll meter or leaf greenness index, has been proposed to analyze leaf chlorophyll content or leaf nitrogen concentration through a non-destructive spectral 
practice (Uddling et al., 2007; Munoz-Huerta et al., 2013). It is widely accepted that tight coordination between the SPAD readings and plant nitrogen status in apple trees as well as citrus, grapevine, wheat, rice, maize, oak, sycamore and maple (Castelli et al., 1996; Argenta et al., 2004; Jifon et al., 2005; Percival et al., 2008; Cerovic et al., 2015; Treder et al., 2016). The SPAD value assigned on the principles of leaf transmittance or reflectance of a red and an infrared light provides immediate and valuable approaches to assess the relative amount of leaf nitrogen (Markwell et al., 1995). While differences in the leaf color in early spring may have been observed among cultivars and flowering and non-flowering spurs of the same cultivar, previous research on 'Amasya' is limited.

Within the tree canopy, the leaf area of fruit trees is a vital component favoring orchard productivity. Various methods have been used to assess the leaf area in the orchard (Breda, 2003; Demirsoy, 2009; Mora et al., 2016; Bairam et al., 2017; Atay et al., 2019). Generally, these methods take into account shoot leaves, or total leaf area represented the ratio of leaf to a specific area of soil. Indeed, spur leaves and shoot leaves growth vary spatially in an apple tree (Van den Ende, 2018). However, for reflecting the potential of the spurs, the information on the spur leaf area is crucial.

In the present study, the SPAD and spur leaf area were investigated in flowering and nonflowering spur leaves of 'Amasya' and six common apple cultivars 'Granny Smith', 'Braeburn', 'Jerseymac', 'Cripps Pink', 'Mondial Gala', and 'Golden Reinders'. The objectives were to (i) reveal a detailed description of spur leaf characteristics in 'Amasya' cultivar, (ii) compare commercially important apple cultivars which exhibit varied branching and bearing behaviors by evaluating the SPAD and leaf area of spur leaves, (iii) to disclose and quantify the SPAD of flowering and nonflowering spur leaves in apple trees.

\section{Materials and Methods}

The study was carried out at Fruit Research Institute, Egirdir-Isparta in Turkey, in 2018 on a fiveyear-old apple trees cv. 'Amasya', 'Braeburn', 'Granny Smith', 'Cripps Pink', 'Jerseymac', 'Golden Reinders', and 'Mondial Gala', grafted onto M.9 rootstock. Trees were planted at $4.0 \mathrm{~m}$ row spacing and $1.0 \mathrm{~m}$ tree spacing and trained as a trellis spindle system with minimal pruning. Orchard management practices, including irrigation, nutrition, pest, disease, and weed control, were performed according to local commercial orchards.

The experimental design was randomized blocks with three replications (two trees each). The SPAD and spur leaf area values were obtained in flowering (Figure 1a) and non-flowering spurs (Figure 1b), sampled randomly, in the last week of April, nearly 5-7 days after full blooming, when the spur leaves were steady. The data were collected from sixty tagged spurs (30 for flowering and 30 for non-flowering) for each cultivar. The SPAD values were obtained using a portable chlorophyll meter (SPAD-502Plus, Konica Minolta, Japan) between 12:00 and 14:30 each measurement day. Three successive readings were taken from the three uppermost fully expanded leaves of spurs tagged. The mean of the three measurements was taken as the mean SPAD value of a spur.

Spur leaf area of the same tagged spurs for each cultivar was visually ranked on a scale of 1 to 5 $\left(1=0-10 \mathrm{~cm}^{2}\right.$, progressively to $5=>41 \mathrm{~cm}^{2}$ spur leaf area (Figure 2). Using this scale, established in previous experiments, is time-saving for predicting the vigorous and weak spurs in mature apple trees.

All statistical analyses and graphs were performed using $\mathrm{R}$ statistical software version 4.1.2 ( $R$ Core Team, 2021). When the F-test was significant in the one-way analysis of variance (ANOVA), means were separated using the Least Significant Difference (LSD) test ('agricolae'

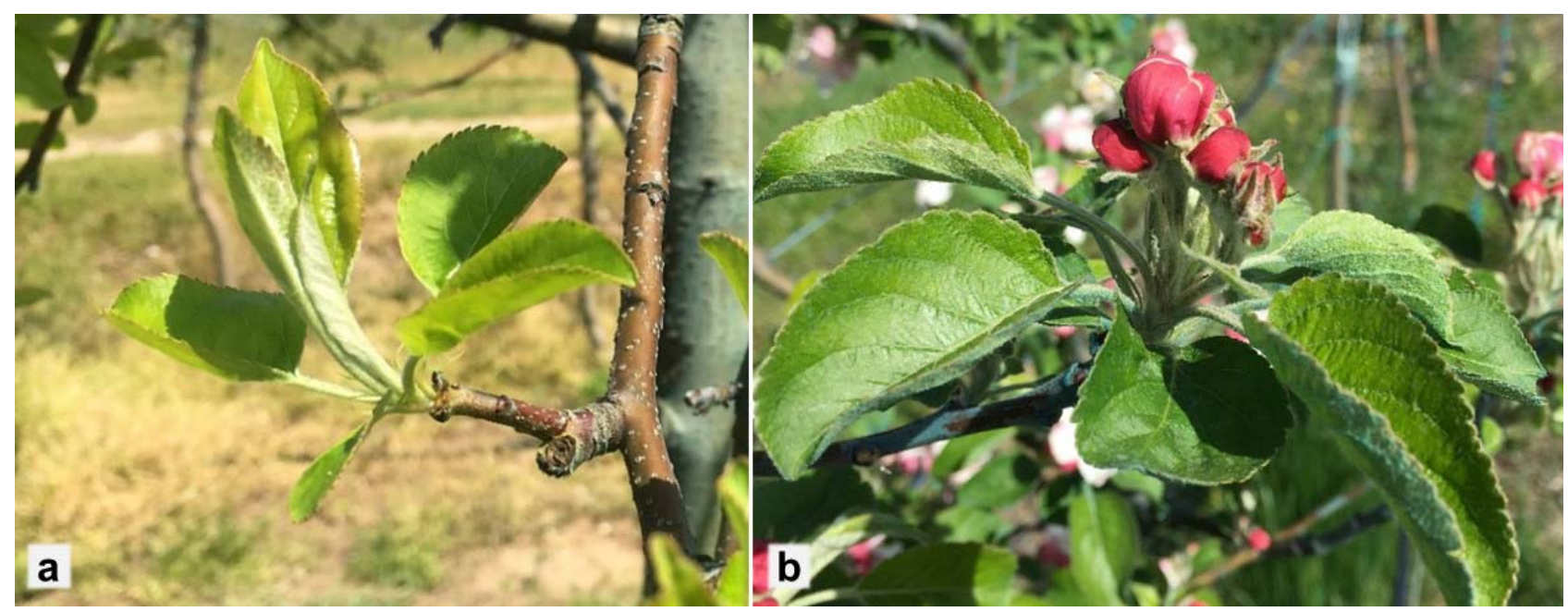

Figure 1. (a) Non-flowering and (b) flowering spurs with spur leaves in apple. 
1

$\left(0-10 \mathrm{~cm}^{2}\right)$

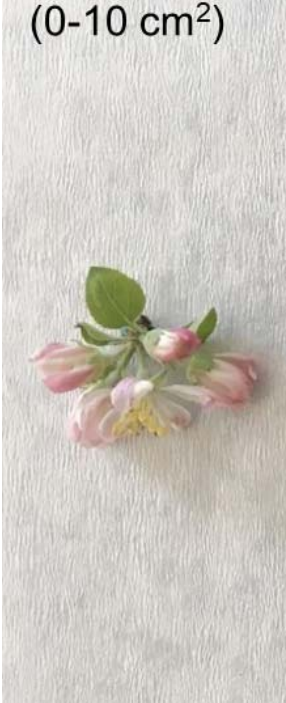

2 $\left(11-20 \mathrm{~cm}^{2}\right)$
3
4
5

$$
\left(21-30 \mathrm{~cm}^{2}\right) \quad\left(31-40 \mathrm{~cm}^{2}\right)
$$
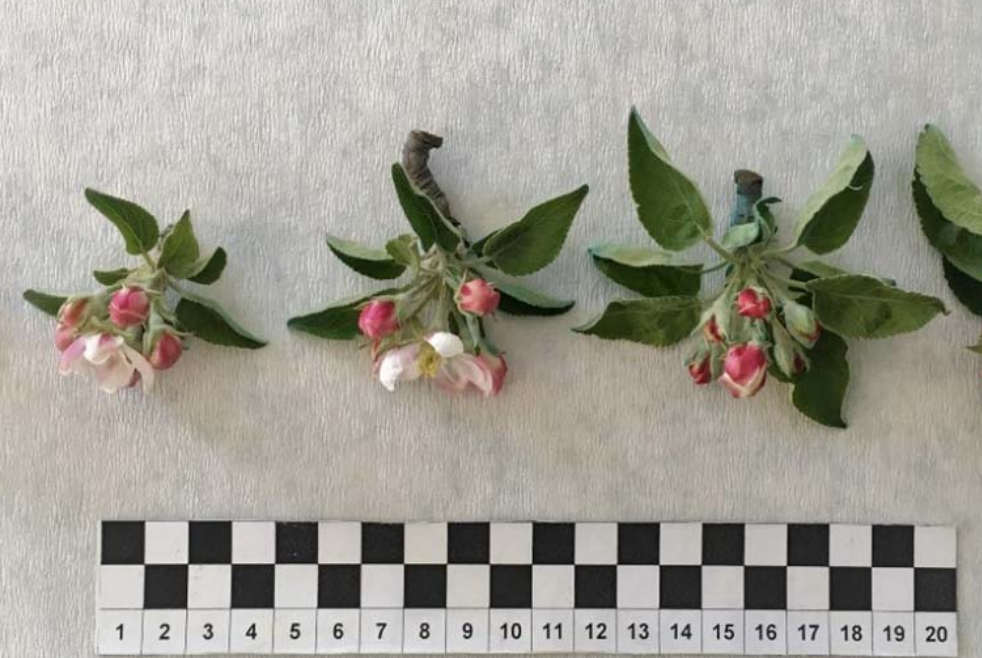

Figure 2. Changes in spur leaf areas in apples and the scale values of total spur leaf area according to a 5-point scale $\left(1: 0-10 \mathrm{~cm}^{2}, 2: 11-20 \mathrm{~cm}^{2}, 3: 21-30 \mathrm{~cm}^{2}, 4: 31-40 \mathrm{~cm}^{2}\right.$ and $5:$ more than $\left.41 \mathrm{~cm}^{2}\right)$.

package). A correlation analysis was performed with the 'PerformanceAnalytics' package to investigate the relationship level between SPAD and spur leaf area values. Box plot and violin graphs were created with the 'ggplot2' package.

\section{Results and Discussion}

When apple trees were at full bloom individual flowering and non-flowering spurs of each cultivar were tagged and separated to examine spur leaf attributes. SPAD values were varied from 45.73 to 25.91 and differed among the cultivars and spur type $(P=0.001)$. The median SPAD values were higher in all cultivars' flowering spurs than nonflowering spurs. The median SPAD values in 'Amasya' were 31.55 and 26.05 for the flowering and non-flowering spurs, respectively, which were relatively low when considering the cultivars studied. 'Golden Reinders' showed pretty similar SPAD values to 'Amasya' (median values 32.00 and 27.20 for flowering and non-flowering spurs, respectively). The flowering spurs of 'Cripps Pink' displayed the highest SPAD value (median=44.85), followed by the flowering spurs of 'Braeburn' (median=41.80). In non-flowering spurs, the lowest mean for SPAD values were observed in 'Amasya' (median=26.05) and 'Golden Reinders' cultivars (median=27.20), while the highest values were recorded from 'Granny Smith' (34.65) and 'Jerseymac' (35.55). SPAD values of 'Mondial Gala' did not differ significantly by spur type (Figure 3 ).

The greenness index determined by SPAD is an indirect measurement of the chlorophyll content of leaves (Markwell et al., 1995; Uddling et al., 2007). SPAD differences between cultivars in our study indicated the changes in their chlorophyll content.
As reported in previous studies, the SPAD readings is a robust and satisfactory method to estimate the leaf chlorophyll concentrations or leaf nitrogen content, which is a significant component of chlorophyll molecule structure (Rostami et al., 2008; Brunetto et al., 2012; Romero et al., 2013; Benati et al., 2021). Moreover, the relationship between leaf chlorophyll content and SPAD values may be affected by the changes in cultivars, environmental factors, and management strategies (Argenta et al., 2004; Munoz-Huerta et al., 2013; Xiong et al., 2015). The high variability of the SPAD among the cultivars observed in this study can be attributed to their wide range of flowering and fruiting patterns and growth habits. Biennial cultivars such as 'Amasya' and 'Golden Reinders' displayed relatively Iow mean SPAD values. However, SPAD reached relatively high values for the cultivars with annual bearing capacity such as 'Cripps Pink' and 'Braeburn'.

Moreover, most previous studies using SPAD indicators focused on the nitrogen nutritional status to adjust fertilizer management practices during critical plant growth periods (Wang et al., 2006; Xiong et al., 2015; Cerovic et al., 2015; Benati et al., 2021). Our results found a better relationship between the SPAD and spur type (flowering vs nonflowering) for each cultivar. The potential of using the SPAD for yield indicator purposes has been evaluated for grain cereals, such as maize (Bishnu, 2020; Szulc et al., 2021), rice (Zhang et al., 2019; Hou et al., 2021), but it is underutilized in fruit trees. The current study is the first to disclose and quantify the relationship between flowering, and nonflowering spur leaves for SPAD measurements in apples and particularly in the Turkish cultivar 'Amasya'. For all cultivar when spurs had flowers, the SPAD values were much higher in the current 


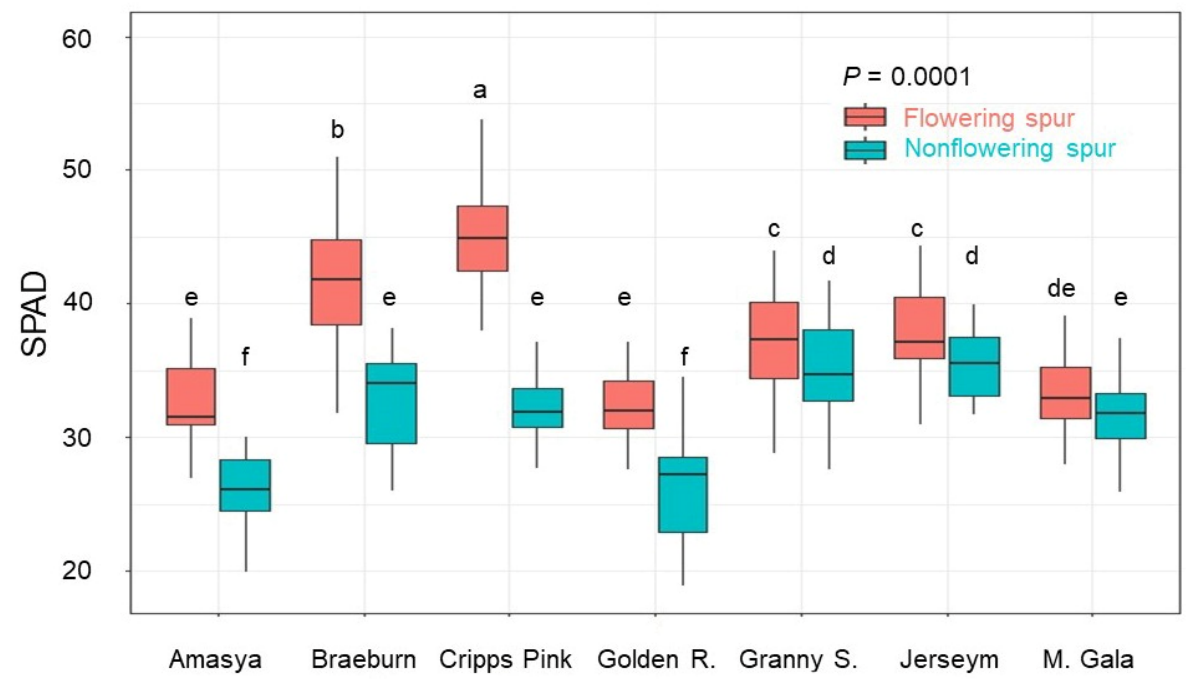

Figure 3. Box plot representation of leaf Soil Plant Analysis Development (SPAD) readings in apple cultivars for each spur leaf category (flowering and non-flowering). The bold horizontal line indicates the median value of SPAD values. The whiskers below and above the boxes denote the minimum and maximum SPAD values, respectively. Different letters indicate statistically different values at $P<0.0001$ considering both flowering and non-flowering spurs of all the cultivars together.

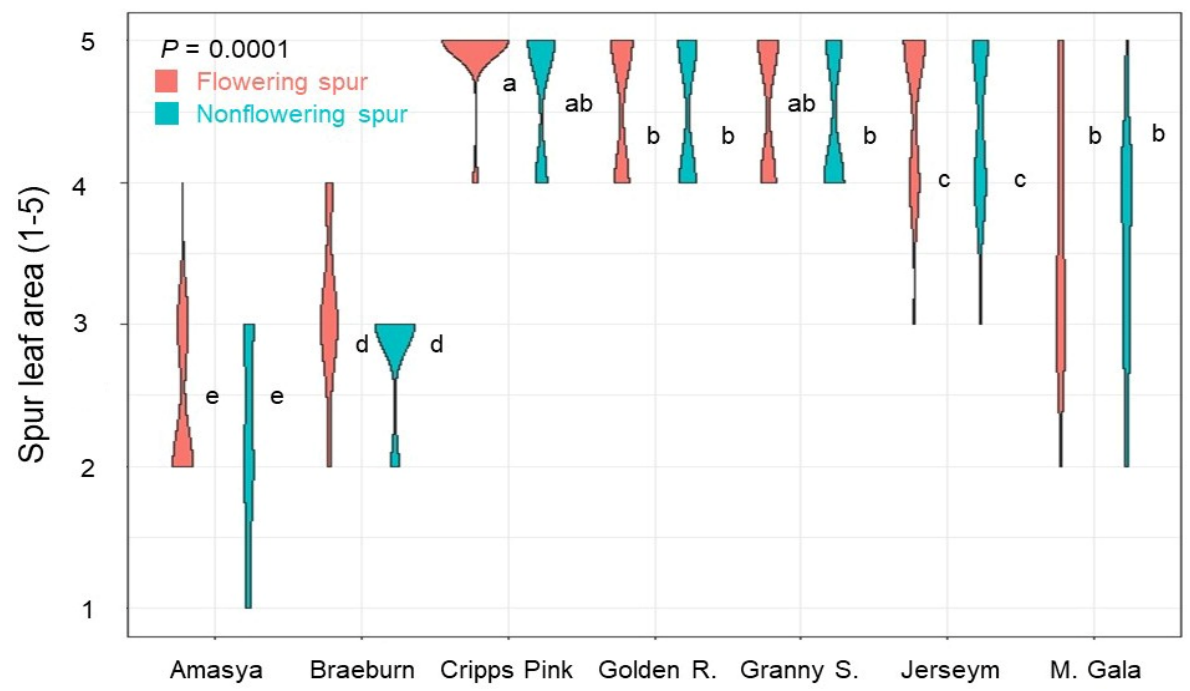

Figure 4. Distribution of spur leaf area in apple cultivars for the two bearing statuses (flowering and non-flowering) considering together the seven cultivars. The expansion and shrinkage of the letter-value plots denote their corresponding quantiles. Different letters indicate statistically different values at $P<0.0001$, considering all the cultivars' flowering and non-flowering spurs.

study, which confirms that decline in chlorophyll content or SPAD values coincided with a gradual decline in productivity. There were significant differences in spur leaf area between cultivars $(P<0.001)$. The spur bearing behavior had no direct effect on the leaf area of the cultivar. A slight difference was observed among flowering and nonflowering spur leaf areas in the cultivars 'Cripps Pink' and 'Granny Smith'. Spur leaf area was relatively high in 'Cripps Pink' with the mean values 4.93 and 4.70 for flowering and non-flowering spur, respectively. 'Granny Smith' also showed relatively high spur leaf area values (mean values 4.63 and 4.47 for flowering and non-flowering spur, respectively). The flowering and non-flowering spurs of other cultivars showed similar distributions with no differences statistically for spur leaf area. 'Golden Reinders' (mean values 4.57 and 4.43 for flowering and non-flowering spur, respectively) showed a similar spur leaf area pattern to 'Mondial Gala' (mean values 4.60 and 4.53 for flowering and non-flowering spur, respectively) for flowering and non-flowering spur. However, there was a greater distribution in 'Mondial Gala' for flowering and nonflowering spur. The latter the main spur leaf area were determined at $3.73,3.43,3.07$ and 2.83 for flowering and non-flowering spurs of the cultivars 'Jerseymac' and 'Braeburn', respectively. A significantly lower spur leaf area was found in 'Amasya' with mean values 2.40 and 2.20 for flowering and non-flowering spur, respectively (Figure 4). 
In previous studies, shoot leaves or total leaf areas of different apple cultivars have been described (Wünsche and Palmer, 1997; Lauri and Kelner, 2001; Knerl et al., 2018). However, to our knowledge, there are limited reports on the spur leaf area of the cultivars we studied in the current study. Indeed, the spur leaf area is one of the critical factors for improved productivity of apple cultivars (Ferree and Schmid, 2004). The presence of a sufficiently large leaf area per spur in apple is a significant factor favoring fruit set and quality (Ferree et al., 2001). Different spur leaf areas were observed in our study depending on the cultivar. The lowest spur leaf area was determined in 'Amasya', whereas the highest spur leaf area was in 'Cripps Pink'. Like all yield components, spur leaf area can typically vary depending on the genotype (Ferree and Palmer, 1982; Elsysy and Hirst, 2017), probably due to differences in their photosynthetic performances (Proctor and Palmer, 1991). Generally, it was determined that the spur leaf area was more prominent in the cultivars with superior yield and fruit quality, except for 'Braeburn'.

Interestingly, no statistical difference was observed between flowering and non-flowering spur leaf areas within the same cultivars, unlike the SPAD value. A relatively weak growth for flowering buds than for vegetative buds is expected chiefly in apple trees since the presence of the flowers/fruits can reduce the amount of carbon required for growth, as previously shown in other studies (Costes, 2003; Willaume et al., 2004; Lauri et al., 2008). However, these studies generally considered shoot leaves, and this prediction is not entirely relevant for spur leaves. The current study examined the spur leaves, which are often more vigorous to initiate flowers. Indeed, weak spurs are not expected to be florally induced, which could explain the similarity in spur leaf area between flowering and non-flowering spur.

The role of SPAD in the spur leaf area was highlighted in the correlation plot illustrated in Figure 5 , which clearly showed that the SPAD value was positively correlated with spur leaf areas. This positive impact can be attributed to the relationship between photosynthesis and SPAD values, as previously observed in other studies (Thompson et al., 1996; Miah et al., 1997; Pallas et al., 2018). Increased photosynthetic activity may likely develop nutrient status and leaf growth of the spurs. These results appear to confirm the observations of Vrignon-Brenas et al. (2019). They suggested that decreasing SPAD value accompanies the lower leaf area.

\section{Conclusion}

To conclude, this research shows the corresponding changes in spur leaf characteristics of 'Amasya' and six common apple cultivars. We determined a significant variability in the SPAD and spur leaf area amongst cultivars/ flowering and nonflowering spurs. 'Amasya' had a relatively low SPAD value and spur leaf area compared to other cultivars. It is vital to have good growth of spur leaves to maximize the productivity of apple trees. Therefore, the knowledge of spur leaf properties of the cultivars studied here could be helpful to organize the management practices or breeding programs. Furthermore, SPAD readings were higher for flowering spurs than non-flowering spurs for all cultivars. The SPAD may play an essential role in estimating apple yielding potential. This study would be the basis for future research over many environmental conditions and long years.

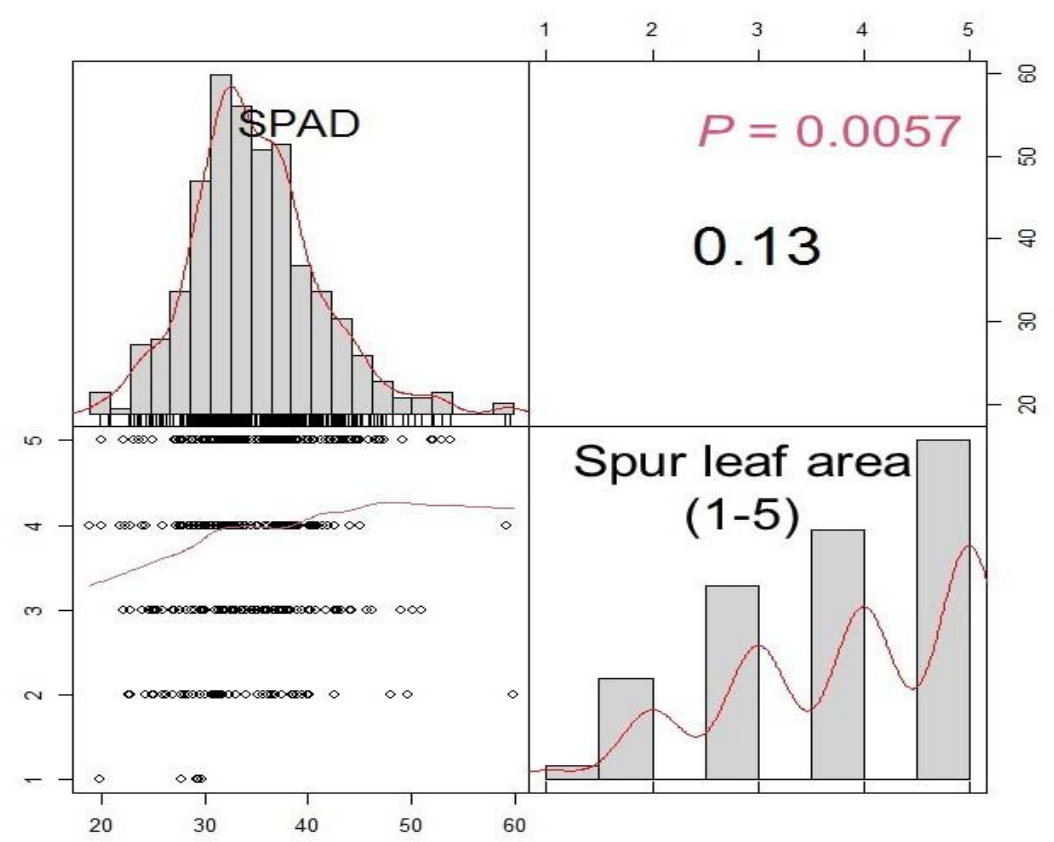

Figure 5. Correlation analysis between Soil Plant Analysis Development (SPAD) value and spur leaf area in flowering and non-flowering spurs of studied apple cultivars. 


\section{References}

Argenta, G., Ferreira da Silva, P., \& Sangoi, L. (2004). Leaf relative chlorophyll content as an indicator to predict nitrogen fertilization in maize. Ciência Rural, 34:1379-1387.

Atay, A.N., Özongun, S., Seymen, T., Bayav, A., \& Atay, E. (2016). Variability and heritability of floral development in apple full-sib offsprings. Genetika, 48:383-394.

Atay, A.N., Atay, E., Lauri, P.E., Kunter, B., \& Kantoglu, K.Y. (2018). Phenotyping gamma-ray-induced mutant population of 'Amasya' apple for architectural traits, precocity, floral phenology and fruit characteristics. Scientia Horticulturae, 233:195-203.

Atay, E., Crete, X., Loubet, D., \& Lauri, P.E. (2019). A moderate regulated deficit irrigation does not negatively affect flowering, fruit-set and return-bloom in a late apple cultivar. Acta Horticulturae, 1253:6370.

Bairam, E., Delaire, M., Le Morvan, C., \& Buck-Sorlin, G. (2017). Models for predicting the architecture of different shoot types in apple. Frontiers in Plant Science, 8:65.

Benati, J.A., Nava, G., \& Mayer, N.A. (2021). SPAD index for diagnosis of nitrogen status in 'Esmeralda' peach. Revista Brasileira de Fruticultura Jaboticabal, 43:(e093).

Bishnu, P.K. (2020). SPAD value varies with age and leaf of maize plant and its relationship with grain yield. BMC Research Notes, 13:475.

Breda, N.J.J. (2003). Ground-based measurements of leaf area index: a review of methods, instruments and current controversies Journal of Experimental Botany, 54: 2403-2417.

Brunetto, G., Trentin, G., Ceretta C., Girotto E., Lorensini F., Miotto A., Moser, G.R.Z., \& Melo, G. W. de. (2012). Use of the SPAD-502 in estimating nitrogen content in leaves and yield in grapevines in soils with different texture. American Journal of Plant Sciences, 3:15461561.

Castelli, F., Contillo, R., \& Miceli F (1996). Nondestructive determination of leaf chlorophyll content in four crop species. Journal of Agronomy and Crop Science, 177:275-283.

Cerovic, Z.G., Ghozlen, N.B., Milhade, C., Obert, M., Debuisson, S., \& Le Moigne M. (2015). Nondestructive diagnostic test for nitrogen nutrition of grapevine (Vitis vinifera L.) based on Dualex leafclip measurements in the field. Journal of Agricultural and Food Chemistry, 63:3669-3680.

Costes, E. (2003). Winter bud content according to position in 3-year-old branching systems of 'Granny Smith' apple. Annual Botany, 92:581-588.

Demirsoy, H. (2009). Leaf area estimation in some species of fruit tree by using models as a nondestructive method. Fruits, 64:45-51.

Elsysy, M.A., \& Peter M.H. (2017). The role of spur leaves, bourse leaves, and fruit on local flower formation in apple: an approach to understanding biennial bearing. HortScience, 52: 1229-1232.

Ferree, D.C., \& Palmer, J.W. (1982). Effect of spur defoliation and ringing during bloom on fruiting, fruit mineral level, and net photosynthesis of Golden Delicious apple. Journal of the American Society for Horticultural Science, 107:1182-6

Ferree, D., Bishop, B., Schupp, J., Tustin, D., \& Cashmore, W. (2001). Influence of flower type, position in the cluster and spur characteristics on fruit set and growth of apple cultivars. Journal of Horticultural Science and Biotechnology, 76:1-8.

Ferree, D.C., \& Schmid, J.C. (2004). Spur leaf and flower characteristics of apple cultivars in the $1995 \mathrm{NE}-183$ trial. Journal of the American Pomological Society, 58:90-97.

Hou, W., Shen, J., Xu, W., Khan, M.R., Wang, Y., Zhou, X., Gao, Q., Murtaza, B., \& Zhang, Z. (2021). Recommended nitrogen rates and the verification of effects based on leaf SPAD readings of rice. PeerJ, 9:e12107.

Jifon, J.L., Syvertsen, J.P., \& Whaley, E. (2005). Growth environment and leaf anatomy affect nondestructive estimates of chlorophyll and nitrogen in Citrus sp. leaves. Journal of the American Society for Horticultural Science, 130:152-158.

Knerl, A., Anthony, B., Serra, S., \& Musacchi, S. (2018). Optimization of leaf area estimation in a high-density apple orchard using hemispherical photography. HortScience, 53:799-804.

Lauri, P.E., \& Kelner, J.J. (2001). Shoot type demography and dry matter partitioning: a morphometric approach in apple (Malus $\times$ domestica). Canadian Journal of Botany, 79:1270-1273.

Lauri, P.E., Bourdel, G., Trottier, C., \& Cochard, H. (2008). Apple shoot architecture: evidence for strong variability of bud size and composition and hydraulics within a branching zone. New Phytology, 178:798807.

Mora, M., Avila, F., Carrasco-Benavides, M., Maldonado, G., Olguín-Cáceres, J., \& Fuentes, S. (2016). Automated computation of leaf area index from fruit trees using improved image processing algorithms applied to canopy cover digital photograpies, Computers and Electronics in Agriculture, 123:195202.

Markwell, J., Osterman, J.C., \& Mitchell, J.L. (1995). Calibration of the Minolta SPAD-502 leaf chlorophyll meter. Photosynth Research, 46:467-472.

Miah, M.N.H, Yoshida, T., \& Yamamoto, Y. (1997). Effect of nitrogen application during ripening period on photosynthesis and dry matter production and its impact on yield and yield components of semidwarf iniica rice varieties under water culture conditions. Soil Science and Plant Nutrition, 43:205-217.

Munoz-Huerta, R.F., Guevara-Gonzalez, R.G., Contreras-Medina, L.M., Torres-Pacheco, I., PradoOlivarez, J., \& Ocampo-Velazquez, R.V. (2013). A review of methods for sensing the nitrogen status in plants: Advantages, disadvantages and recent advances. Sensors, 13:10823.

Pallas, B., Bluy, S., Ngao, J., Martinez, S., Clément-Vidal, A., Kelner, J.J., \& Costes, E. (2018). Growth and carbon balance are differently regulated by tree and shoot fruiting contexts: an integrative study on apple genotypes with contrasted bearing patterns, Tree Physiology, 389:1395-1408.

Percival, G.C., Keary, I.P., \& Noviss, K. (2008). The potential of a chlorophyll content SPAD meter to quantify nutrient stress in foliar tissue of sycamore (Acer pseudoplatanus), English Oak (Quercus robur). Annals of Forest Science, 77:11-30.

Proctor, J.T.A., \& Palmer, J.W. (1991). The role of spur and bourse leaves of three apple cultivars on fruit set, growth, and calcium content. Journal of Horticultural Science, 66:275-282.

R Core Team (2021). R: A language and environment for statistical computing. R Foundation for Statistical 
Computing, Vienna, Austria. URL https://www.Rproject.org/.Foundation.

Romero, I., Garcia-Escudero, E., \& Martin, I. (2013). Leaf blade versus petiole analysis for nutritional diagnosis of Vitis vinifera L. cv. Tempranillo. American Journal of Enology and Viticulture, 64:50-64.

Rostami, M., Koocheki, A., Mahallati, M.N., \& Kafi, M. (2008). Evaluation of chlorophyll meter (SPAD) data for prediction of nitrogen status in corn (Zea mays L.). American-Eurasian Journal of Agricultural \& Environmental Sciences, 3:79-85.

Szulc, P., Bocianowski, J., Nowosad, K., Zielewicz, W., \& Kobus-Cisowska, J. (2021). SPAD leaf greenness index: green mass yield indicator of maize (Zea mays L.), genetic and agriculture practice relationship. Plants, 10:830.

Thompson, J.A., Schweitzer, L.E., \& Nelson, R.L. (1996). Association of specific leaf weight, an estimate of chlorophyll, and chlorophyll concentration with apparent photosynthesis in soybean. Photosynth Research, 49:1-10.

Treder, W., Klamkowski, K., Kowalczyk, W., Sas, D., \& Wójcık, K. (2016). Possibilities of using image analysis to estimate the nitrogen nutrition status of apple trees. Zemdirbyste-Agriculture, 103:319-326.

Uddling, J., Gelang-Alfredsson, J., Piikki, K., Pleijel, H. (2007). Evaluating the relationship between leaf chlorophyll concentration and SPAD-502 chlorophyll meter readings. Photosynth Research, 91:37-46.
Van den Ende, B. (2018). Why apples need both spur and shoot leaves to grow. https://www.treefruit.com.au. Date accessed: December 01, 2021.

Vrignon-Brenas, S., Aurélie, M., Romain, L., Shiva, G., Alana, F., Myriam, D., Gaëlle, R., \& Anne, P. (2019). Gradual responses of grapevine yield components and carbon status to nitrogen supply. OENO One, 53:2431.

Wang, S., Zhu, Y., Jiang, H., \& Cao, W. (2006). Positional differences in nitrogen and sugar concentrations of upper leaves relate to plant $\mathrm{N}$ status in rice under different N rates. Field Crop Research, 96:224-234.

Willaume, M., Lauri, P.E., \& Sinoquet, H. (2004). Light interception in apple trees influenced by canopy architecture manipulation. Trees, 18:705-713.

Wünsche, J.N., \& Palmer, J.W. (1997). Comparison of non-destructive methods of estimating leaf area in apple tree canopies. Acta Horticulturea, 451:701-708.

Xiong, D., Chen, J., Yu, T., Gao, W., Ling, X., Li, Y., Peng, S., \& Huang, J. (2015). SPAD-based leaf nitrogen estimation is impacted by environmental factors and crop leaf characteristics. Scientific Reports, 5:13389.

Zhang, K., Liu, X., Tahir Ata-Ul-Karim, S., Lu, J., Krienke, B., Li, S., Cao, Q., Zhu, Y., Cao, W., \& Tian, Y. (2019). Development of chlorophyll-meter-index-based dynamic models for evaluation of high-yield Japonica rice production in Yangtze River Reaches. Agronomy, 9:106. 